\title{
Diversidade bacteriana da rizosfera de genótipos de milho contrastantes na eficiência de uso de fósforo
}

\author{
Christiane Abreu de Oliveira ${ }^{(1)}$, Ivanildo Evódio Marriel(2), Eliane Aparecida Gomes ${ }^{(2)}$, \\ Ubiraci Gomes de Paula Lana( ${ }^{(2)}$, Maria Rita Scotti ${ }^{(1)}$ e Vera Maria Carvalho Alves ${ }^{(2)}$
}

(1)Universidade Federal de Minas Gerais, Departamento de Botânica, Caixa Postal 486, CEP $31270-901$ Belo Horizonte, MG.
E-mail: paiva.christiane@yahoo.com.br, mrita@icb.ufmg.br (2)Embrapa Milho e Sorgo, Caixa Postal 151, CEP 35701-970 Sete Lagoas, MG.
E-mail: imarriel@cnpms.embrapa.br, eliane@cnpms.embrapa.br, ubiraci@cnpms.embrapa.br, vera@cnpms.embrapa.br

Resumo - O objetivo deste trabalho foi avaliar a diversidade funcional e genética de bactérias associadas à rizosfera de genótipos de milho contrastantes quanto à eficiência de uso de fósforo, por meio do teste de fontes de carbono no sistema EcoPlate e da eletroforese em gel de gradiente desnaturante (DGGE) dos fragmentos amplificados dos genes $16 \mathrm{~S}$ ribossomais (rDNA) das bactérias. Foram coletadas amostras de solo da rizosfera de linhagens e híbridos contrastantes quanto à eficiência de uso de fósforo, cultivados em Latossolo Vermelho-Escuro fase cerrado, com baixo e alto teor de P. Bactérias da rizosfera de híbridos e linhagens eficientes, sob estresse de $\mathrm{P}$, analisadas pelo sistema EcoPlate, tenderam a se agrupar conforme a análise de componentes principais, o que indica que utilizaram fontes de carbono semelhantes. Não houve diferença na diversidade bacteriana, analisada pela DGGE, entre bactérias associadas a genótipos eficientes e ineficientes no uso de P. Com base no sequenciamento do $16 \mathrm{~S}$ rDNA, foi verificado que a rizosfera de genótipos de milho sob estresse de P parece selecionar grupos específicos de bactérias. A estrutura populacional genética e metabólica de bactérias da rizosfera foi mais influenciada pelo teor de fósforo no solo do que pela eficiência das plantas em usar o fósforo.

Termos para indexação: Zea mays, deficiência de fósforo, ecologia microbiana, PCR-DGGE, sistema EcoPlate.

\section{Bacterial diversity in the rhizosphere of maize genotypes contrasting for phosphorus use efficiency}

\begin{abstract}
The objective of this work was to evaluate the functional and genetic diversity of bacteria associated to the rhizosphere of maize genotypes contrasting for phosphorus use efficiency by means of the EcoPlate carbon source test and denaturing gradient gel electrophoresis (DGGE) of amplified 16S ribosomal DNA (rDNA) fragments of bacteria. Rhizosphere soil samples of maize genotypes (hybrids and lineages) contrasting for phosphorus use efficiency cultivated in an Oxisol with high and low P content were collected. Bacteria from the rhizosphere of P-efficient maize genotypes under P stress conditions analyzed by the EcoPlate system tended to group together according to main components analysis, which indicates that these bacteria used similar carbon sources. Microbial diversity analyzed by DGGE did not differ between P-efficient and inefficient maize genotypes. Based on the $16 \mathrm{~S}$ rDNA fragment sequencing, the rhizosphere of maize genotypes growing on low-P soils seemed to select specific bacteria species. The genetic and metabolic structure of the rhizosphere bacterial community was more strongly influenced by the level of $\mathrm{P}$ in the soil than by the genotypes with contrasting P-use efficiency.
\end{abstract}

Index terms: Zea mays, phosphorus deficiency, microbial ecology, PCR-DGGE, EcoPlate system.

\section{Introdução}

Práticas de manejo dos componentes biológicos do solo, associadas ao uso de cultivares eficientes, constituem tecnologias importantes para uma agricultura sustentável. A tolerância de alguns cultivares aos estresses nutricionais, principalmente de fósforo, pode estar relacionada à ocorrência de determinados microrganismos na rizosfera das plantas (Hinsinger, 2001; Marschner et al., 2006; Picard et al., 2008). $\mathrm{O}$ fósforo (P) é o nutriente menos móvel no solo e menos disponível para as plantas, e a sua deficiência no solo de cerrado tem sido um fator limitante para o crescimento da planta de milho (Novais \& Smyth, 1999; Hinsinger, 2001). Quando as plantas crescem em um meio deficiente em $\mathrm{P}$, as raízes podem excretar 
substâncias funcionais, que constituem um importante mecanismo de adaptação à variação de $\mathrm{P}$ no ambiente (Marschner et al., 2001, 2006; Li et al., 2004). A quantidade e a qualidade dos exsudatos liberados pela raiz também alteram a química do solo e influenciam a comunidade bacteriana que coloniza a rizosfera e utiliza esses exsudados como fonte de carbono (Grayston et al., 1998; Baudoin et al., 2001; Richardson et al., 2009). A composição desses exsudatos pode variar com a idade e o genótipo da planta, o metabolismo, a condição nutricional, o tipo de estresse e outros fatores ambientais (Liu et al., 2004; Barea et al., 2005; Richardson et al., 2009).

A composição da comunidade bacteriana na rizosfera pode afetar a disponibilidade de $\mathrm{P}$ para as plantas (Marschner et al., 2006). Com o aumento de práticas agrícolas com baixos insumos, há crescente interesse no manejo das comunidades bacterianas do solo para incrementar o crescimento das plantas. No entanto, poucos estudos que demonstrem a eficiência na adaptabilidade a condições de estresse de $\mathrm{P}$, relacionados à população bacteriana rizosférica, têm sido conduzidos em cultivares de milho.

O conhecimento sobre a estrutura e a função dos microrganismos associados às plantas agrícolas tropicais ainda é incipiente. Essa limitação é, em parte, devida às dificuldades metodológicas na identificação dos microrganismos e da incapacidade de se isolar populações representativas. Além disso, menos de $20 \%$ dos microrganismos do solo podem ser cultivados em laboratório (Prosser, 2002), e aqueles que conseguem crescer em meio de cultura não são necessariamente metabólicos ou numericamente dominantes no meio de origem (Nannipieri et al., 2003).

Métodos que avaliam a diversidade metabólica e métodos moleculares têm sido utilizados para alcançar maior número de espécies e avaliar melhor a estrutura da comunidade bacteriana (Kirk et al., 2004). Entre eles pode-se citar a diversidade funcional com o sistema EcoPlate (Biolog, Inc., Hayward, CA, EUA), que mede a intensidade de utilização de diferentes fontes de carbono pelas bactérias e produz um padrão metabólico (Garland \& Mills, 1991; Garland, 1996; Gomez et al., 2006), os métodos moleculares, como a análise do rDNA ribossomal (16S rDNA) para bactérias, a partir da amplificação por PCR, e a eletroforese em gel de gradiente desnaturante (DGGE). Esta última técnica permite identificar polimorfismo nos fragmentos de mesmo tamanho do DNA obtido de amostras da microbiota do solo (Muyzer et al., 1993). Alguns estudos têm sido realizados na rizosfera de milho, entretanto, nenhum deles analisou a população bacteriana da rizosfera dessa planta em condições de estresse de P no solo (Gomes et al., 2001; Mota et al., 2002, 2008; Silva et al., 2003).

O objetivo deste trabalho foi avaliar a diversidade funcional e genética de bactérias totais da rizosfera de cultivares de milho eficientes e ineficientes no uso de $\mathrm{P}$, em solos com alta ou baixa disponibilidade desse elemento, por meio do sistema EcoPlate e da eletroforese em gel de gradiente desnaturante (DGGE) dos fragmentos amplificados dos genes $16 \mathrm{~S}$ ribossomais (rDNA) de bactérias.

\section{Material e Métodos}

Amostras de solo rizosférico foram coletadas em um Latossolo Vermelho-Escuro fase cerrado durante o início do florescimento do milho. Os experimentos de campo foram realizados na Embrapa Milho e Sorgo, Sete Lagoas, MG, em delineamento inteiramente casualizado, com três repetições. As amostras de solo rizosférico foram constituídas da porção de solo aderida à raiz de cinco plantas de cada híbrido e linhagem de milho, eficientes (E) e ineficientes (I) na utilização de $\mathrm{P}$, em locais com dois teores de P (alto, $29 \mathrm{mg} \mathrm{dm}^{-3}$; baixo, $\left.3 \mathrm{mg} \mathrm{dm}^{-3}\right)$. Os híbridos utilizados foram HT (E), HS1 (E), HS2 (E), HS3 (I) e HS4 (I); as linhagens, L3 (E), L228 (E), L22 (I). Foram coletadas também, para comparação, amostras de solo não rizosférico de área de baixo teor de $\mathrm{P}(\mathrm{NR})$, solo não rizosférico da área de alto teor de $\mathrm{P}$ (NRP), solo da rizosfera do híbrido triplo em plantio direto [HT (E) PD], solo não rizosférico do plantio direto (NRD) e vegetação natural de cerrado (Mata). O solo da área experimental apresentou as seguintes características: 29,3 e $0,16 \mathrm{mg} \mathrm{dm}^{-3}$ de alto teor de $\mathrm{Pe}$ baixos teores de $\mathrm{Pe} \mathrm{K}$, respectivamente (Mehlich I); pH 5,2 (relação solo:água, 1:2,5); $30 \mathrm{~g} \mathrm{~kg}^{-1}$ de matéria orgânica; $0,25,2,29$ e $0,36 \mathrm{cmolc} \mathrm{kg}^{-1}$ de Al, $\mathrm{Ca}$ e $\mathrm{Mg}$, respectivamente (extrator $\mathrm{KCl} 1 \mathrm{~N}$ ); análise granulométrica de 550, 110 e $340 \mathrm{~g} \mathrm{~kg}^{-1}$ de argila, silte e areia, respectivamente. As amostras de solo para extração de DNA foram mantidas a $-20^{\circ} \mathrm{C}$.

Para determinação da diversidade funcional bacteriana, foi utilizada a metodologia descrita por Zak et al. (1994). As amostras de solo foram 
suspendidas em $90 \mathrm{~mL}$ de solução salina $(0,85 \% \mathrm{NaCl})$ e agitadas em um agitador de bancada (modelo 113, ICELL, Brasil) durante $30 \mathrm{~min}$. Cerca de $5 \mathrm{~mL}$ dessa suspensão foram centrifugados a $1.900 \mathrm{~g}$ (Super T21, Sorvall, EUA) durante $15 \mathrm{~min}$. Alíquotas de $120 \mu \mathrm{L}$ do sobrenadante foram transferidas para cada cavidade das placas EcoPlate (Biolog, Inc., Hayward, CA, EUA), que foram incubadas no escuro durante cinco dias, a $25^{\circ} \mathrm{C}$. A suspensão de células bacterianas foi padronizada inicialmente por meio de diluições seriadas, e cada cavidade das microplacas continha cerca de $10^{4}$ células por mililitro. Essa concentração de células foi padronizada pela leitura da densidade de células em espectrofotômetro (Lambda Bio, PerkinElmer, EUA) e pela contagem em placas. Cada placa é composta por três grupos de 31 substratos diferentes(ácidos carboxílicos, carboidratos, polímeros, aminoácidos, amidos), além do controle (cavidade sem substrato). A leitura das placas foi realizada por meio da medida da cor desenvolvida pela oxidação de substratos durante a respiração dos microrganismos em um espectrofotômetro leitor de placas (Labsystems, MultSkan, MS, EUA), em $590 \mathrm{~nm}$, nos intervalos de $24,48,72,96$ e 120 horas. A leitura de 72 horas foi utilizada para cálculos dos componentes da diversidade funcional por representar o tempo médio entre as leituras realizadas. Os componentes da diversidade funcional, atividade total, diversidade metabólica e índice de Shannon $(\mathrm{H})$ foram estimados de acordo com Zak et al. (1994). Os valores da atividade total foram transformados utilizando-se a média das leituras dos 31 substratos de cada amostra e repetição por AWCD (Average Well Colour Development), por meio da divisão da atividade de utilização dos substratos leitura em absorbância (nm) da cor desenvolvida - em cada cavidade pelo valor médio da leitura da placa inteira (Garland \& Mills, 1991). Os valores acima de zero foram considerados como reação positiva, e evidenciam a utilização de substratos e os valores negativos, a ausência de uso do substrato.

O delineamento experimental foi o inteiramente casualizado com três repetições, dez tratamentos de híbridos e nove tratamentos para as linhagens. A análise estatística foi realizada com o teste de Tukey, para detectar diferenças entre as médias. Os dados de utilização de substratos (S) e da atividade total (transformada) foram utilizados para análise de agrupamento (UPGA, Unweighted Pair-Group Average) com o coeficiente de distância euclidiana e a análise de componentes principais (PCA) por meio do software Statistica, versão 6.0.

O DNA total da população de bactérias foi extraído a partir de $500 \mathrm{mg}$ de solo das amostras descritas, com uso do protocolo do kit FastDNA SPIN Kit for Soil (Qbiogene, BIO 101 Systems, Carlsbad, CA, EUA). Os fragmentos de DNA foram amplificados com os iniciadores universais para bactérias F968 com grampo CG e R1401 (Nübel et al., 1996). A reação de amplificação (PCR) continha um total de $50 \mu \mathrm{L}$ (uma unidade) de Taq DNA polimerase (Invitrogen, Carslbad, CA, EUA), $50 \mu \mathrm{mol} \mathrm{L}^{-1}$ de cada dNTP, 2,5 $\mathrm{mmol} \mathrm{L}^{-1}$ de $\mathrm{MgCl}_{2}, 20 \mathrm{mmol} \mathrm{L}^{-1}$ de Tris-HCl (pH 8,4), $50 \mathrm{mmol} \mathrm{L}^{-1}$ de $\mathrm{KCl}, 0,5 \mu \mathrm{L}$ de formamida deionizada e $0,2 \mu \mathrm{mol} \mathrm{L}^{-1}$ de cada iniciador. O PCR foi realizado em um termociclador modelo 9700 (PerkinElmer, EUA) usando-se: $94^{\circ} \mathrm{C}$ por 2 min, seguido de 30 ciclos de $94^{\circ} \mathrm{C}$ por $1 \mathrm{~min}, 55^{\circ} \mathrm{C}$ por $1 \mathrm{~min} \mathrm{e} 72^{\circ} \mathrm{C}$ por $2 \mathrm{~min}$, com uma extensão final de $10 \mathrm{~min}$ a $72^{\circ} \mathrm{C}$. Os produtos de PCR foram aplicados em gel com $6 \%$ de poliacrilamida, com gradiente de desnaturantes de 45 a $65 \%$. Os gradientes foram formados a partir de soluções estoque de poliacrilamida (6\%) que continha 0 e $100 \%$ de desnaturantes (ureia e formamida deionizada). A eletroforese foi realizada em uma unidade de DGGE D-Code (Biorad, Richmond, EUA) durante 16 horas a $60^{\circ} \mathrm{C}$ e $70 \mathrm{~V}$, em tampão TAE $1 \mathrm{X}\left(40 \mathrm{mmol} \mathrm{L}^{-1}\right.$ Tris-Acetato, $1 \mathrm{mmol} \mathrm{L}^{-1}$ EDTA, $\mathrm{pH} 8,0)$. Após a eletroforese, o gel foi corado com prata de acordo com a metodologia de Creste et al. (2001) e fotografado em câmera digital. Como DNA controle da DGGE, foram utilizadas as espécies de bactérias Escherichia coli, Rhizobium leguminosarum, Agrobacterium tumefaciens, Azospirillum sp. e Bacillus thuringiensis.

Após a DGGE, os padrões de bandas obtidos foram comparados com uso da análise de agrupamento (UPGA, Unweighted Pair-Group Average). As bandas mais proeminentes foram eluídas do gel de DGGE e novamente amplificadas por PCR para posterior identificação das espécies. O produto do PCR foi aplicado em um gel de agarose $1,5 \%(\mathrm{~m} / \mathrm{v})$, corado com brometo de etídio $\left(1 \mu \mathrm{g} \mathrm{mL} \mathrm{mL}^{-1}\right)$ e visualizado em um transluminador de UV Eagle Eye II (Stratagene, La Jolla, CA, EUA). O produto de PCR foi extraído do gel e purificado com uso do Kit QIAquick Gel Extraction (Qiagen, Hilden, Alemanha) e, em seguida, sequenciado com o kit Big Dye Terminator versão 3.1 (Applied Biosystems, Foster City, CA, EUA) em um 
sequenciador ABI Prism 3100 (Applied Biosystems). As sequências obtidas foram identificadas usando o programa BlastN (Altschul et al., 1997) com o banco de dados Genbank (Blast, 2009) e o programa Seqmatch com o banco de dados RDPII (Cole et al., 2003).

\section{Resultados e Discussão}

A atividade de utilização dos substratos medida pelo desenvolvimento de cor (expressa em AWCD) foi diferente ao longo do tempo de incubação para cada amostra de extrato microbiano (Figura 1). A partir de 48 horas de incubação, apareceram distinções entre os extratos microbianos das rizosferas.

Observou-se que os extratos bacterianos da rizosfera dos híbridos HS1 (E) e HS2 (E), cultivados em condições de baixo teor de $\mathrm{P}$ no solo, apresentaram maior atividade de utilização dos substratos que os demais durante o período de incubação das amostras (Figura $1 \mathrm{~A}$ ). Em estudo realizado em condições de casa de vegetação, Brasil (2003) obteve resultados semelhantes de atividade metabólica microbiana na rizosfera desses mesmos genótipos, o que sugere que essa característica é inerente ao híbrido. As linhagens consideradas como eficientes no uso de $\mathrm{P}$ também apresentaram maior atividade de utilização de substratos (Figura $1 \mathrm{~B}$ ) com baixo P. No entanto, o solo rizosférico da linhagem L22 (I) apresentou a mesma diversidade de bactérias $(\mathrm{H})$ em condições de baixo $\mathrm{P}$ no solo (Tabela 1). Isto significa que as bactérias de linhagens eficientes da rizosfera utilizaram os mesmos substratos que as bacterias de linhagem ineficiente, porém com maior intensidade de utilização, demonstrada pelo desenvolvimento de cor. Estudos anteriores mostraram
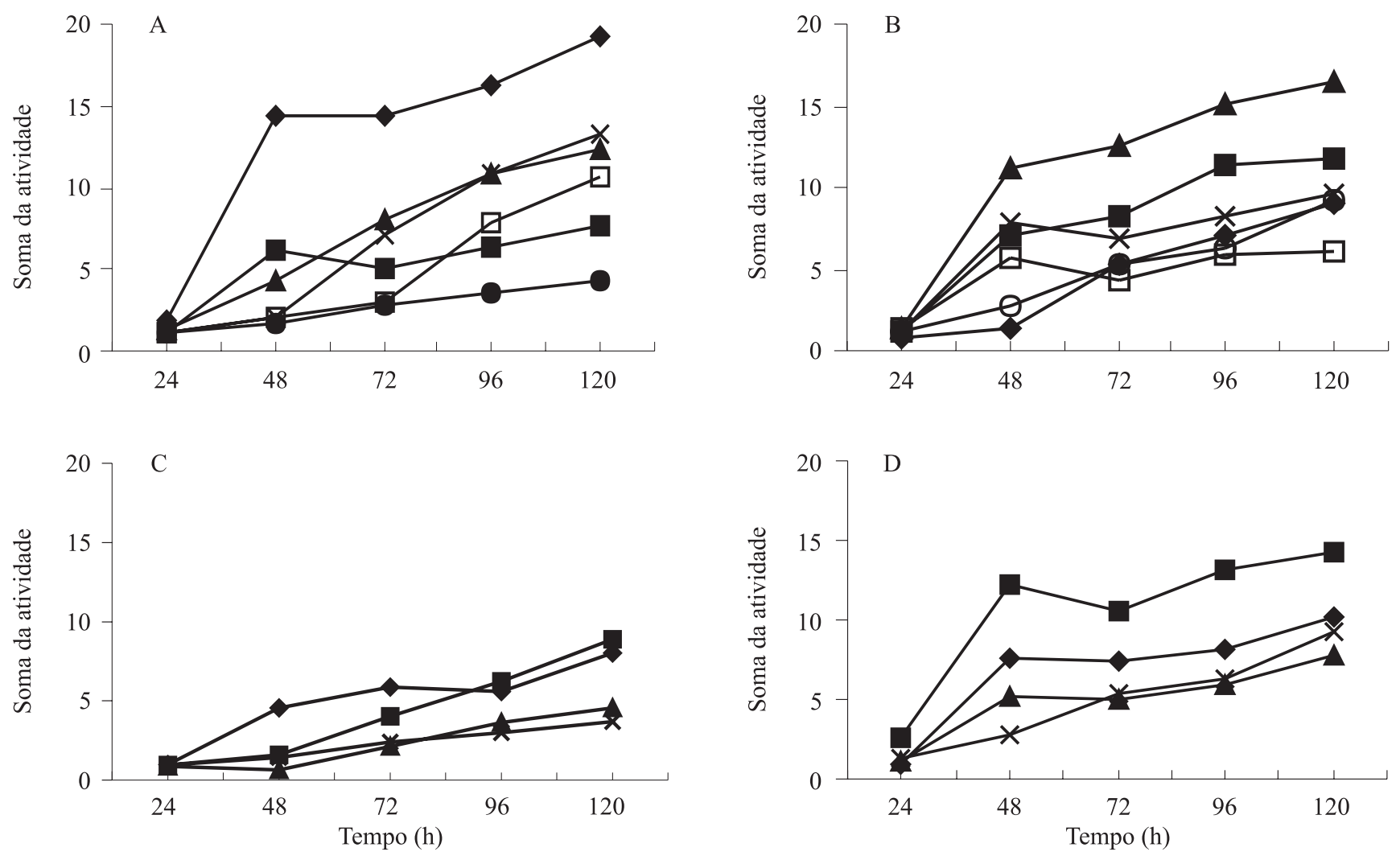

Figura 1. Soma da atividade total/AWCD (leitura em 590 nanômetros) de utilização de fontes de carbono do extrato microbiano em cada amostra de solo rizosférico de híbridos e linhagens cultivadas com alto e baixo teores de P no solo. A, híbridos cultivados com alto teor de P; B, híbridos cultivados com baixo teor de P; C, linhagens cultivadas com alto teor de P; D, linhagens cultivadas com baixo teor de P. Os híbridos: HT (E) $\bullet$, HS1 (E) $\boldsymbol{\square}$, HS2 (E) $\boldsymbol{\Delta}$, HS3 (I) x, HS4 (I) $\square$, NRP (solo não rizosférico com alto teor de P) $\bullet$, e NR (solo rizosférico com baixo teor de P) $\bigcirc$. As Linhagens: L3 (E) $\bullet$, L228 (E) $\boldsymbol{\square}$, L22 (I) $\boldsymbol{\Delta}$, e testemunhas NRP e NR, $\mathrm{x}$. E, refere-se a genótipos eficientes no uso de P; I, refere-se a genótipos ineficientes. 
correlação entre a densidade de células e a taxa de desenvolvimento de cor (Garland \& Mills, 1991; Gomez et al., 2006). Segundo Marschner et al. (2001), a alta taxa de liberação de carbono orgânico pelas raízes favorece o aumento da densidade populacional de microrganismos na rizosfera, especialmente de bactérias, em relação ao restante do solo. Portanto, pode-se sugerir que, na rizosfera de L3 (E) e L228 (E), ocorreu maior liberação de fontes de carbono, que favoreceram maior densidade de células de bactérias em situação de estresse de P. Vários estudos têm demonstrado que diferentes genótipos de planta influenciam a comunidade microbiana presente na rizosfera em razão da diferença na sinalização emitida pelas raízes como exsudatos, especialmente quando as plantas ou genótipos se encontram em situação de estresse mineral, como o de P (Hinsinger, 2001; Barea et al., 2005; Marschner et al., 2006).

$\mathrm{O}$ índice de diversidade de Shannon $(\mathrm{H})$ indica maior diversidade em amostras com maior variedade de utilização de diferentes fontes de carbono. A escala de $\mathrm{H}$ para as placas EcoPlate varia de 0 a 4 (Zak et al., 1994). Na rizosfera dos genótipos estudados, as amostras coletadas apresentaram valores de $\mathrm{H}$ próximos de 3 , com diferença significativa $(\mathrm{p}<0,05)$ entre genótipos eficientes e ineficientes e entre teores de $\mathrm{P}$ para cada cultivar. Houve efeito rizosférico na diversidade de espécies de bactérias para todos os genótipos com baixo P, exceto para HS4 (I). De maneira

Tabela 1. Diversidade metabólica (índice de Shannon, H) de bactérias de amostras de solo rizosférico de cinco híbridos de milho e três linhagens eficientes (E) e ineficientes (I) no uso de $\mathrm{P}$, em 72 horas de incubação em solo não rizosférico da área de baixo P (NR) e de alto teor de P (NRP) e mata ${ }^{(1)}$.

\begin{tabular}{lccc}
\hline Híbridos $^{(2)}$ & $\begin{array}{c}\text { Índice de } \\
\text { Shannon }\end{array}$ & $\begin{array}{c}\text { Linhagens e } \\
\text { testemunhas }\end{array}$ & $\begin{array}{c}\text { Índice de } \\
\text { Shannon }\end{array}$ \\
\hline HT (E) P & $3,09 \mathrm{a}$ & L3 (E) P & $2,42 \mathrm{~b}$ \\
HT (E) & $2,80 \mathrm{a}$ & L3 (E) & $2,74 \mathrm{a}$ \\
HS1 (E) P & $2,33 \mathrm{~b}$ & L228 (E) P & $2,70 \mathrm{a}$ \\
HS1 (E) & $2,81 \mathrm{a}$ & L228 (E) & $2,80 \mathrm{a}$ \\
HS2 (E) P & $2,77 \mathrm{a}$ & L22 (I) P & $2,00 \mathrm{~b}$ \\
HS2 (E) & $2,98 \mathrm{a}$ & L22 (I) & $2,57 \mathrm{a}$ \\
HS3 (I) P & $2,67 \mathrm{a}$ & NR P & $1,93 \mathrm{~b}$ \\
HS3 (I) & $2,74 \mathrm{a}$ & NR & $2,38 \mathrm{~b}$ \\
HS4 (I) P & $2,28 \mathrm{~b}$ & Mata & $2,90 \mathrm{a}$ \\
HS4 (I) & $2,25 \mathrm{~b}$ & - & - \\
\hline
\end{tabular}

(1)Médias seguidas de letras iguais não diferem entre si pelo teste de Tukey, a $5 \%$ de probabilidade. ${ }^{(2)} \mathrm{P}$, genótipos cultivados em teor alto de $\mathrm{P}$; sem a letra $\mathrm{P}$, genótipos cultivados em teor baixo de $\mathrm{P}$. geral, amostras de solo com alto $\mathrm{P}$ tiveram menor diversidade metabólica da comunidade bacteriana quando comparadas às de baixo $P$, independentemente do genótipo (Tabela 1), o que é evidência de que a dosagem de P no solo pode ter influenciado a redução da atividade metabólica de bactérias nesses ambientes. Para o híbrido HT (E) isso não ocorreu, uma vez que a atividade metabólica de utilização de fontes de carbono e a diversidade funcional foram maiores com alto teor de $\mathrm{P}$.

As comunidades bacterianas tiveram perfil distinto de utilização das fontes de carbono dependentemente da origem, como revelou a análise de agrupamento (Figura 2). A comunidade proveniente da rizosfera do híbrido HT em plantio direto (HT E PD) foi distinta da comunidade da rizosfera de HT em plantio convencional [HT (E) e HT(E) P], o que revela o efeito do tipo de cultivo sobre a diversidade funcional das bactérias na rizosfera de milho. Houve a formação de dois principais grupos funcionais de bactérias: um proveniente de solos rizosféricos com alto teor de $\mathrm{P}$ e outro predominante em solos com baixo teor de $\mathrm{P}$, provenientes da rizosfera de genótipos eficientes, principalmente as linhagens eficientes, as quais se agruparam com a mata, sítio de alta diversidade microbiana. Amostras de rizosfera de híbridos (HT e HS2) e linhagens eficientes (L3 e L228) tenderam a agrupar-se (Figuras 3 A e B), o que indica que as bactérias pertencentes a essas amostras fazem uso semelhante de fontes de carbono. A estrutura populacional das bactérias da rizosfera dos genótipos de milho foi mais influenciada pelo teor de $\mathrm{P}$ no solo do que pela eficiência da planta em utilizar esse elemento.

No dendrograma dos microrganismos da rizosfera das linhagens de milho, utilizadas neste trabalho, observouse a formação de um grupo distinto, a dois pontos de distância genética que continha o solo rizosférico das linhagens eficientes e ineficientes cultivadas em solos com baixo teor de $\mathrm{P}$ e solo de mata de cerrado, considerado como de alta diversidade (Figura $4 \mathrm{~A}$ ). Observou-se, também, que o perfil genético da comunidade bacteriana do solo NR com baixo teor de $\mathrm{P}$ foi distinto do perfil genético da população bacteriana na rizosfera das linhagens nessa mesma condição de $\mathrm{P}$ no solo, o que indica que houve efeito rizosférico dessas linhagens, dependendo do teor de P no solo.

Não ocorreram diferenças, na diversidade microbiana, entre a rizosfera de linhagens eficientes e não eficientes (Figura $4 \mathrm{~A}$ ), o que sugere que o teor de $\mathrm{P}$ no solo foi o fator determinante da diferença na estrutura da população bacteriana total da rizosfera 
de linhagens de milho contrastantes no uso de P. Essa ausência de diferença da comunidade microbiana entre linhagens de plantas observada por DGGE também foi

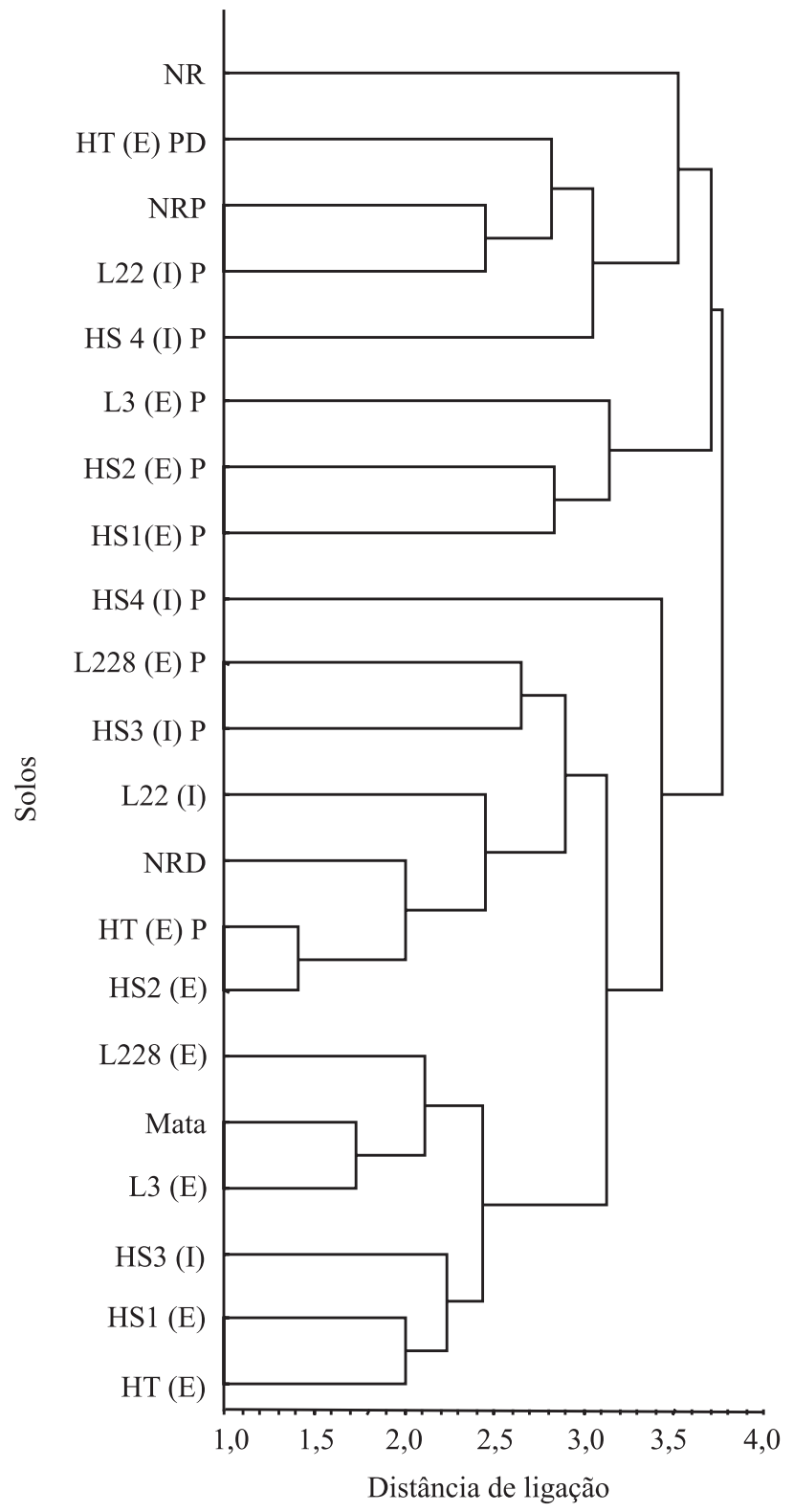

Figura 2. Análise de agrupamento (UPGA) da comunidade bacteriana dos solos, conforme a utilização dos substratos de cada tratamento ( 72 horas de incubação). Os solos foram cultivados com híbridos - HT (E), HS1 (E), HS2 (E), HS3 (I), HS4 (I) HT (E) - e linhagens - L3 (E), L228 (E), L22 (I) - de milho com elevada eficiência (E) ou ineficiência (I) no uso de $\mathrm{P}$, em condições de elevado (P) ou de baixo suprimento desse nutriente (ausência da letra P). NR, solo não rizosférico com baixo $\mathrm{P}$; NRP, solo não rizosférico da com alto teor de P; NRD, solo não rizosférico de plantio direto; PD, plantio direto. encontrada por Gomes et al. (2001), Mota et al. (2002, 2008) e Silva et al. (2003), ao estudar a diversidade e a dinâmica de comunidades bacterianas na rizosfera de cultivares de milho no Cerrado, usando TGGE e DGGE. Mota et al. (2008) encontraram diferenças no padrão de bandas de DGGE ao estudar a rizosfera de linhagens de milho em condições de estresse de alumínio comparadas com linhagens cultivadas sem estresse desse elemento. Semelhanças na composição da comunidade bacteriana de amostras de solo
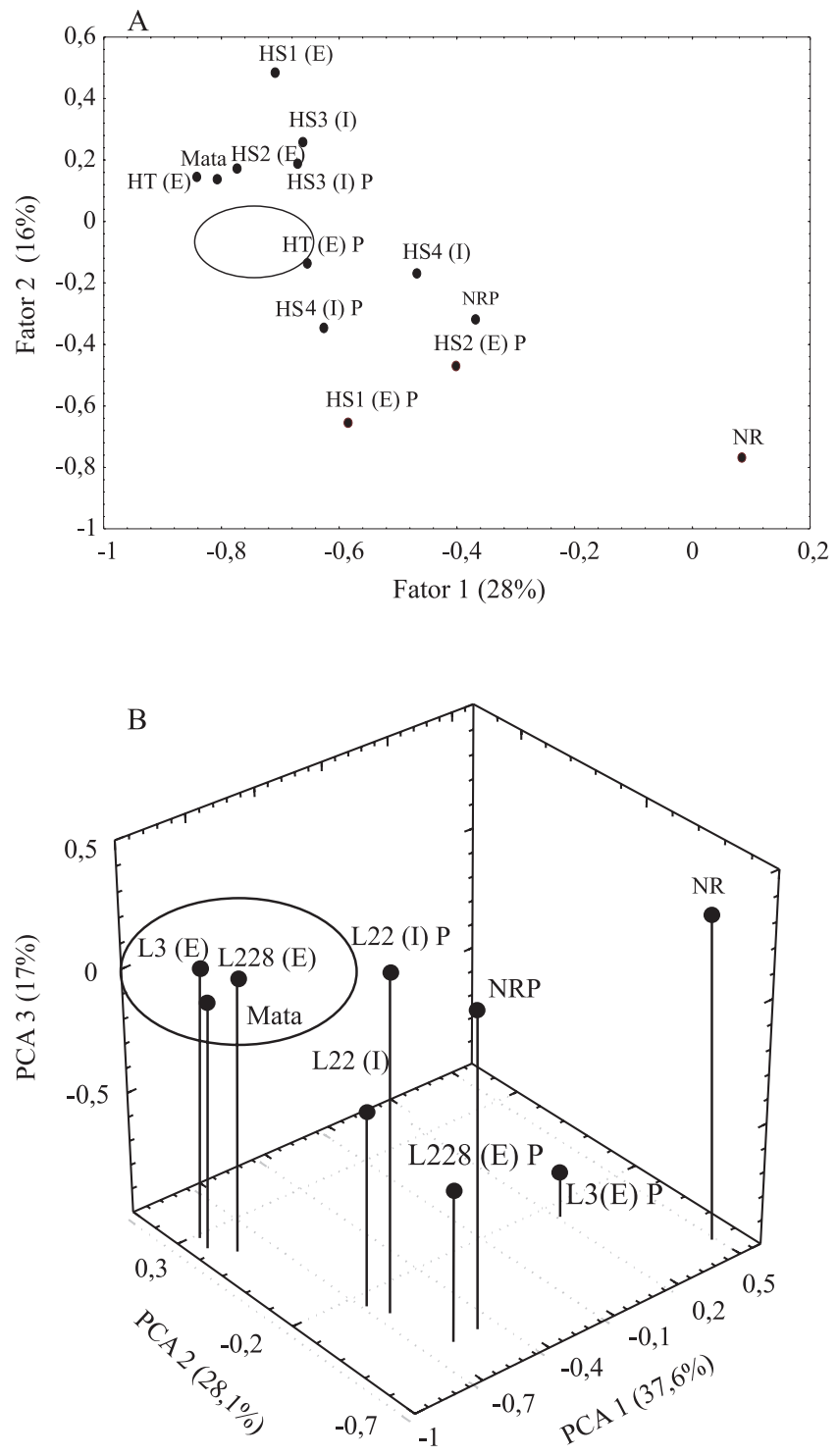

Figura 3. Análise bidimensional dos híbridos (A) e análise tridimensional das linhagens (B) por componentes principais (PCA), conforme a utilização de substratos após 72 horas de incubação. Híbridos e linhagens eficientes (E) ou ineficientes (I) no uso do fósforo. P, alto teor de P no solo. 
rizosférico de linhagens eficientes foram observadas na análise de componentes principais do perfil metabólico (Figura $3 \mathrm{~B}$ ). Isso indica que podem ter ocorrido mudanças nas densidades populacionais de grupos específicos metabolicamente ativos sem alteração da densidade total na rizosfera desses genótipos. O padrão de bandas gerado na DGGE, pela população microbiana presente na rizosfera dos híbridos, revelou um perfil semelhante de bandas que indica não existir diferenças entre híbridos eficientes e ineficientes e entre os teores de P (Figura 4 B).

Algumas bandas - A, C, H e J, respectivamente (Figura 4, Tabela 2) -, identificadas como bactérias da subdivisão Gammaproteobacteria, da ordem
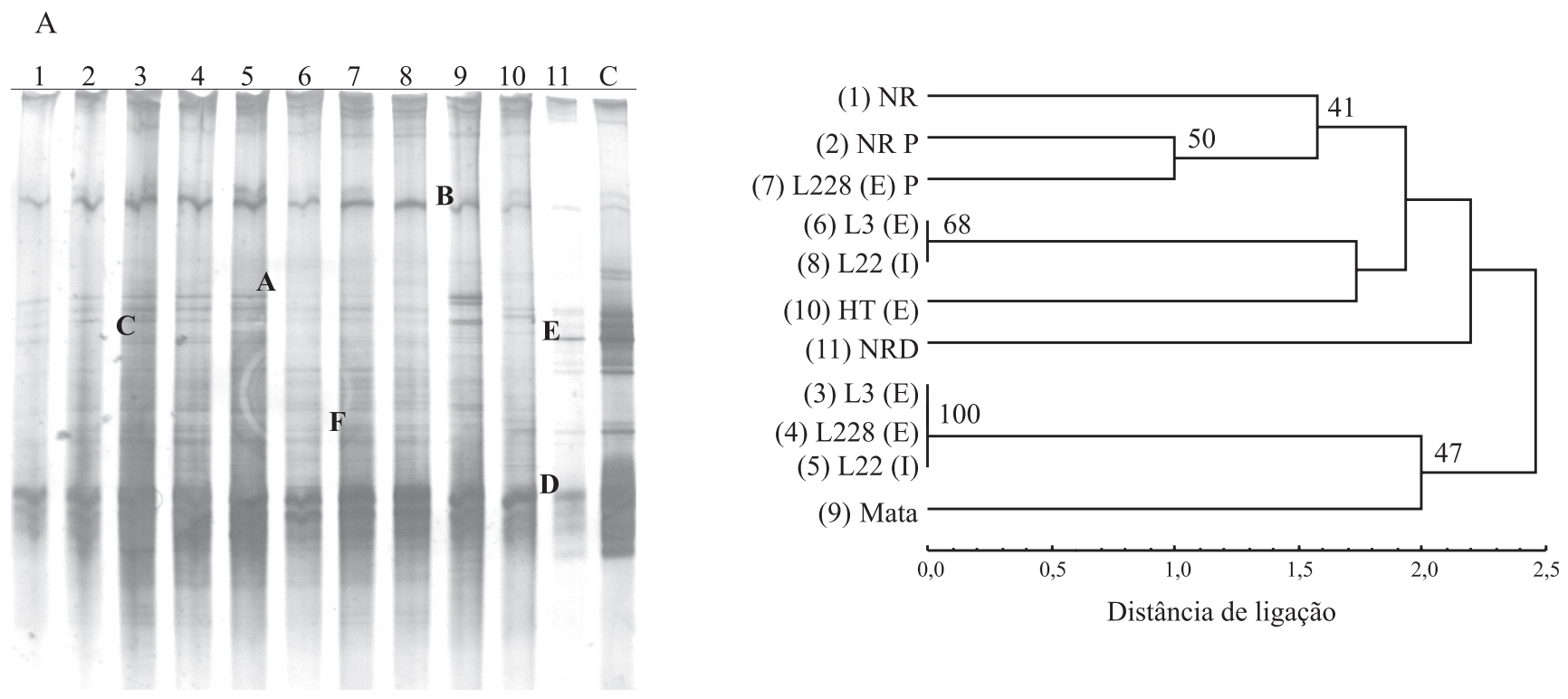

B

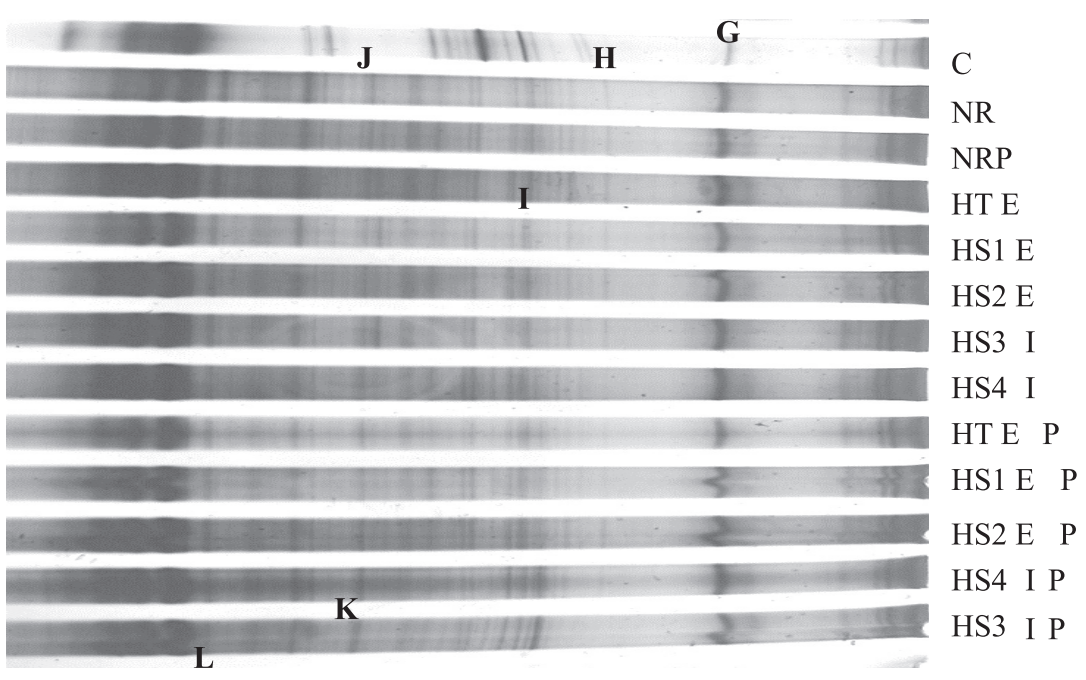

Figura 4. Perfis de DGGE das comunidades bacterianas do solo não rizosférico de linhagens (A) e híbridos (B) de milho, eficientes (E) ou ineficientes (I) no uso do P, cultivadas em alto (P) e baixo teores de P. O dendrograma foi construído pelo coeficiente de distância euclidiana e pelo método de UPGMA. As fileiras C contêm os controles do DGGE com DNA puro de bactérias. Solos: Mata, NR e NRP, não rizosférico em parcelas com baixo e alto teor de P. As bandas relacionadas nos géis de DGGE (letras A a L) são identificadas na Tabela 2. 
Desulfuromonadales, do gênero Ruminococcus e da espécie Bacillus algicola, aparecem na rizosfera de genótipos do solo com estresse de $\mathrm{P}$ e em alguns casos desaparecem ou se tornam mais fracas com alto teor de P. Essa diferença pode estar relacionada a mudanças na rizosfera desses genótipos, ocasionadas pelo estresse de P (Marschner et al., 2006), o que confirma os dados encontrados utilizando-se a técnica de Biolog. Os resultados do presente trabalho estão de acordo com os encontrados por Benizri et al. (2002) e Baudoin et al. (2003), que constataram mudanças na estrutura populacional de espécies de bactérias em estudos sobre o efeito da aplicação direta de exsudatos radiculares de milho na microbiota.

Como o PCR-DGGE da região rDNA 16S avalia a comunidade bacteriana predominante existente na rizosfera, metabolicamente ativa ou não (Prosser, 2002), mudanças no perfil metabólico de cada espécie podem ser responsáveis pelas diferenças constatadas

Tabela 2. Identificação das bandas (amplificadas duas vezes) das amostras de DGGE obtidas de linhagens (bandas A até F) e de híbridos (bandas $\mathrm{G}$ até L) de milho contrastantes quanto ao uso de fósforo, pelos softwares SeqMatch com o banco RDP (Ordem), e BlastN com o banco NCBI (primeiro "hit").

\begin{tabular}{|c|c|c|}
\hline \multirow{2}{*}{$\begin{array}{l}\text { Banda de } \\
\text { DGGE }^{(1)}\end{array}$} & \multicolumn{2}{|c|}{ Grupo genético } \\
\hline & Identificação RDP (ordem) ${ }^{(2)}$ Id & $\begin{array}{l}\text { Identificação BlastN/número } \\
\text { de acesso/similaridade }\end{array}$ \\
\hline & \multicolumn{2}{|c|}{ DGGE - Linhagens e testemunhas } \\
\hline A & Gammaproteobacteria & $\begin{array}{c}\text { Uncultured soil bacterium/ } \\
\text { AY326587/98\% }\end{array}$ \\
\hline B & Gammaproteobacteria & - \\
\hline $\mathrm{C}$ & $\begin{array}{c}\text { Proteobacteria } \\
\text { (Desulfuromonadales) }\end{array}$ & $\begin{array}{l}\text { Uncultured bacterium/ } \\
\text { AF269005/89\% }\end{array}$ \\
\hline $\mathrm{D}$ & $\begin{array}{l}\text { Uncultured bacterium } \\
\text { (Ordem Anaerolinaeles) }\end{array}$ & $\begin{array}{l}\text { Uncultured bacterium/ } \\
\text { AJ536876/88\% }\end{array}$ \\
\hline $\mathrm{E}$ & Unclassified bacteria & $\begin{array}{l}\text { Uncultured bacterium/ } \\
\text { AJ536876/93\% }\end{array}$ \\
\hline \multirow[t]{2}{*}{$\underline{F}$} & Bacillus algicola (Bacillales) & - \\
\hline & \multicolumn{2}{|c|}{ DGGE - híbridos } \\
\hline G & Bacilli (Bacillales) & - \\
\hline $\mathrm{H}$ & Bacillus algicola (Bacillales) & - \\
\hline I & Uncultured bacterium (Aquificales) & - \\
\hline $\mathrm{J}$ & Ruminococcus sp. (Clostridiales) & - \\
\hline K & Alphaproteobacteria (Rickettsiales) & - \\
\hline $\mathrm{L}$ & Unclassified bacteria & $\begin{array}{l}\text { Uncultured bacterium/ } \\
\text { AJ536876.1/90\% }\end{array}$ \\
\hline
\end{tabular}

${ }^{(1)}$ Bandas de DGGE relacionadas nos géis da Figura 4. ${ }^{(2)}$ Resultado do primeiro "hit" das sequências no banco de dados NCBI e programa BlastN, acesso em 2/1/2007. (3) Resultado mais provável de classificação das sequências no banco de dados RDP com o programa Seqmatch. entre linhagens eficientes e ineficientes usando o EcoPlate. Entretanto, o uso de EcoPlate também tem sido questionado por gerar resultados apenas da fração da comunidade representada pelos microrganismos de crescimento mais rápido e cultiváveis, o que reflete o potencial metabólico e não a diversidade in situ (Nannipieri et al., 2003; Kirk et al., 2004). Portanto, os resultados encontrados ressaltam a importância da utilização conjunta das duas técnicas, o que também foi sugerido por outros autores (Kirk et al., 2004), uma vez que, por meio do DGGE, foi possível avaliar grupos bacterianos não cultiváveis em meio de cultura por Biolog EcoPlate, o que possibilita maior entendimento da interação microrganismo-planta. Estudos futuros com uso de iniciadores específicos de gêneros ou espécies de bactérias poderão ser realizados para o refinamento da análise de DGGE.

Os mecanismos da interação planta-microrganismos para melhoria do uso de $\mathrm{P}$, realizados neste estudo e em outros anteriores (Oliveira et al., 2009), fornecem subsídios para a seleção de genótipos eficientes nos programas de melhoramento genético de milho e contribui para o manejo efetivo de sistemas agrícolas no Cerrado brasileiro (Alves et al., 1999; Picard et al., 2008).

\section{Conclusões}

1. A estrutura da comunidade bacteriana da rizosfera de genótipos de milho contrastantes no uso de fósforo é mais influenciada pelo teor de P no solo do que pelo genótipo.

2. Em plantas de milho cultivadas em solo com baixo suprimento de $\mathrm{P}$, ocorre maior diversidade funcional de bactérias do que em solo sem deficiência desse elemento.

3. Não há diferença entre o padrão de bandas gerado pela técnica de DGGE para as linhagens eficientes e não eficientes.

4. A técnica de EcoPlate é mais eficiente que a de DGGE para detectar as diferenças na estrutura da população rizosférica de bactérias entre genótipos eficientes e ineficientes na aquisição de P.

\section{Referências}

ALTSCHUL, S.F.; MADDEN, T.L.; SCHÄFFER, A.A.; ZHANG, J.; ZHANG, Z.; MILLER, W.; LIPMAN, D.J. Gapped BLAST and 
PSI-BLAST: a new generation of protein database search programs. Nucleic Acids Research, v.25, p.3389-3402, 1997.

ALVES, V.M.C.; MAGALHÃES, J.V.; VASCONCELLOS, C.A.; NOVAIS, R.F.; BAHIA FILHO, A.F.C.; FRANÇA, G.E.; OLIVEIRA, C.A.; FRANÇA, C.C.M. Acúmulo de nitrogênio e de fósforo em plantas de milho afetadas pelo suprimento parcial de fósforo às raízes. Revista Brasileira de Ciência do Solo, v.23, p.299-305, 1999.

BAREA, J.-M.; POZO, M.J.; AZCÓN, R.; AZCÓN-AGUILAR, C. Microbial co-operation in the rhizosphere. Journal of Experimental Botany, v.56, p.1761-1778, 2005.

BAUDOIN, E.; BENIZRI, E.; GUCKERT, A. Impact of artificial root exudates on the bacterial community structure in bulk soil and maize rhizosphere. Soil Biology and Biochemistry, v.35, p.1183-1192, 2003.

BAUDOIN, E.; BENIZRI, E.; GUCKERT, A. Metabolic fingerprint of microbial communities from distinct maize rhizosphere compartments. European Journal of Soil Biology, v.37, p.85-93, 2001.

BENIZRI, E.; DEDOURGE, O.; DIBATTISTA-LEBOEUF, C.; PIUTTI, S.; NGUYEN, C.; GUCKERT, A. Effect of maize rhizodeposits on soil microbial community structure. Applied Soil Ecology, v.21, p.261-265, 2002.

BLAST. Basic Local Alignment Search Tool. Disponível em: <www.ncbi.nlm.nih.gov/blast>. Acesso em: 15 dez. 2009.

BRASIL, E.C. Mecanismos envolvidos na eficiência de aquisição de fósforo em genótipos de milho. 2003. 161p. Tese (Doutorado) - Universidade Federal de Lavras, Lavras.

COLE, J.R.; CHAI, B.; MARSH, T.L.; FARRIS, R.J.; WANG, Q.; KULAM, S.A.; CHANDRA, S.; MCGARRELL, D.M.; SCHMIDT, T.M.; GARRITY, G.M.; TIEDJE, J.M.; The Ribosomal Database Project (RDP-II): previewing a new autoaligner that allows regular updates and the new prokaryotic taxonomy. Nucleic Acids Research, v.31, p.442-443, 2003.

CRESTE, S.; TULLMAN-NETO, A.; FIGUEIRA, A. Detection of single sequence repeat polymorphisms in denaturing polyacrilamide sequencing gels by silver staining. Plant Molecular Biology Reporter, v.19, p.299-306, 2001.

GARLAND, J.L. Patterns of potential C source utilization by rhizosphere communities. Soil Biology and Biochemistry, v.28, p.223-230, 1996.

GARLAND, J.L.; MILLS, A.L. Classification and characterization of heterotrophic microbial communities on the basis of patterns of community-level sole-carbon-source utilization. Applied and Environmental Microbiology, v.57, p.2351-2359, 1991.

GOMES, N.C.M.; HEUER, H.; SCHÖNFELD, J.; COSTA, R.; MENDONÇA-HAGLER, L.; SMALLA, K. Bacterial diversity of the rhizosphere of maize (Zea mays) grown in tropical soil studied by temperature gradient gel electrophoresis. Plant and Soil, v.232, p.167-180, 2001.

GOMEZ, E.; FERRERAS, L.; TORESANI, S. Soil bacterial functional diversity as influenced by organic amendment application. Bioresource Technology, v.97, p.1484-1489, 2006.
GRAYSTON, S.J.; WANG, S.; CAMPBELL, C.D.; EDWARDS, A.C. Selective influence of plant species on microbial diversity in the rhizosphere. Soil Biology and Biochemistry, v.30, p.369-378, 1998.

HINSINGER, P. Bioavailability of soil inorganic $\mathrm{P}$ in the rhizosphere as affected by root-induced chemical changes: a review. Plant and Soil, v.237, p.173-195, 2001.

KIRK, J.L.; BEAUDETTE, L.A.; HART, M.; MOUTOGLIS, P.; KLIRONOMOS, J.N.; LEE, H.; TREVORS, J.T. Methods of studying soil microbial diversity. Journal of Microbiological Methods, v.58, p.169-188, 2004.

LI, Q.C.; ALLEN, H.L.; WOLLUM, A.G. Microbial biomass and bacterial functional diversity in forest soils: effects of organic matter removal, compaction, and vegetation control. Soil Biology and Biochemistry, v.36, p.571-579, 2004.

LIU, Y.; MI, G.; CHEN, F.; ZHANG, J.; ZHANG, F. Rhizosphere effect and root growth of two maize (Zea mays L.) genotypes with contrasting P efficiency at low P availability. Plant Science, v.167, p.217-223, 2004.

MARSCHNER, P.; SOLAIMAN, Z.; RENGEL, Z. Rhizosphere properties of Poaceae genotypes under P-limiting conditions. Plant and Soil, v.283, p.11-24, 2006.

MARSCHNER, P.; YANG, C.-H.; LIEBEREI, R.; CROWLEY, D.E. Soil and plant specific effects on bacterial community composition in the rhizosphere. Soil Biology and Biochemistry, v.33, p.1437-1445, 2001.

MOTA, F.F. da; GOMES, E.A.; MARRIEL, I.E.; PAIVA, E.; SELDIN, L. Bacterial and fungal communities in bulk soil and rhizospheres of aluminum-tolerant and aluminum-sensitive maize (Zea mays L.) lines cultivated in unlimed and limed Cerrado soil. Journal of Microbiology and Biotechnology, v.18, p.805-814, 2008.

MOTA, F.F. da; NÓBREGA, A.; MARRIEL, I.E.; PAIVA, E.; SELDIN, L. Genetic diversity of Paenibacillus polymyxa populations isolated from the rhizosphere of four cultivars of maize (Zea mays) in Cerrado soil. Applied Soil Ecology, v.20, p.119-132, 2002.

MUYZER, G.; DE WAAL, E.C.; UITTERLINDEN, A.G. Profiling of complex microbial populations by denaturing gradient gel electrophoresis analysis of polymerase chain reaction-amplified genes coding for 16S rRNA. Applied and Environmental Microbiology, v.59, p.695-700, 1993.

NANNIPIERI, P.; ASCHER, J.; CECCHERINI, M.T.; LANDI, L.; PIETRAMELLARA, G.; RENELLA, G. Microbial diversity and soil functions. European Journal of Soil Science, v.54, p.655-670, 2003.

NOVAIS, R.F. de; SMYTH, T.J. Fósforo em solo e planta em condições tropicais. Viçosa: UFV, 1999. 399p.

NÜBEL, U.; ENGELEN, B.; FELSKE, A.; SNAIDR, J.; WIESHUBER, A.; AMANN, R.I.; LUDWIG, W.; BACKHAUS, H. Sequence heterogeneities of genes encoding 16S rRNAs in Paenibacillus polymyxa detected by temperature gradient gel electrophoresis. Journal of Bacteriology, v.178, p.5636-5643, 1996. 
OLIVEIRA, C.A.; SÁ, N.M.H.; GOMES, E.A.; MARRIEL, I.E.; SCOTTI, M.R.; GUIMARÃES, C.T.; SCHAFFERT, R.E.; ALVES, V.M.C. Assessment of the mycorrhizal community in the rhizosphere of maize (Zea mays L.) genotypes contrasting for phosphorus efficiency in the acid savannas of Brazil using denaturing gradient gel electrophoresis (DGGE). Applied Soil Ecology, v.41, p.249-258, 2009.

PICARD, C.; BARUFFA, E.; BOSCO, M. Enrichment and diversity of plant-probiotic microorganisms in the rhizosphere of hybrid maize during four growth cycles. Soil Biology and Biochemistry, v.40, p.106-115, 2008.

PROSSER, J.I. Molecular and functional diversity in soil micro-organisms. Plant and Soil, v.244, p.9-17, 2002.
RICHARDSON, A.E.; BAREA, J.-M.; MCNEILL, A.M.; PRIGENT-COMBARET, C. Acquisition of phosphorus and nitrogen in the rhizosphere and plant growth promotion by microorganisms. Plant and Soil, v.321, p.305-339, 2009.

SILVA, K.R.A. da; SALLES, J.F.; SELDIN, L.; VAN ELSAS, J.D. Application of a novel Paenibacillus-specific PCR-DGGE method and sequence analysis to assess the diversity of Paenibacillus spp. in the maize rhizosphere. Journal of Microbiological Methods, v.54, p.213-231, 2003.

ZAK, J.C.; WILLING, M.R.; MOORHEAD, D.L.; WILDMAN, H.G. Functional diversity of microbial communities: a quantitative approach. Soil Biology and Biochemistry, v.26, p.1101-1108, 1994.

$\overline{\text { Recebido em } 30 \text { de abril de } 2009 \text { e aprovado em } 27 \text { de outubro de } 2009}$ 